\title{
Mid-term to long-term results of primary arthroscopic Bankart repair for traumatic anterior shoulder instability: a retrospective study
}

Benjamin Panzram ${ }^{1,2^{*}}$, Yasser Kentar ${ }^{1+}$, Michael Maier $^{1}$, Thomas Bruckner ${ }^{3}$, Pit Hetto ${ }^{1}$ and Felix Zeifang ${ }^{4}$

\begin{abstract}
Background: The arthroscopic method offers a less invasive technique of Bankart repair for traumatic anterior shoulder instability. The aim of the study is to determine the mid-/long-term functional outcome, failure rates and predictors of failure after primary arthroscopic Bankart repair for traumatic anterior shoulder instability.

Methods: A total of 100 patients were primarily operated using arthroscopic Bankart repair after traumatic anterior shoulder instability. Medical records were retrospectively reviewed, and patients were assessed using postal questionnaire after a mean follow-up of 8.3 years [3-14]. Clinical assessment was performed using Constant score, Rowe score, and American Shoulder and Elbow Surgeons score.

Results: The overall recurrence rate was 22\%. The Kaplan-Meier failure-free survival estimates. were $80 \%$ at 5 years and $70 \%$ at 10 years. Nearly half (54.5\%) of recurrences occurred at 2 years postoperative. Compared with normal shoulder, there were statistical differences in all 3 scores. Failure rate was significantly affected by age at the time of surgery with $86 \%$ of recurrence cases observed in patients aged 30 years or younger. Nevertheless, Younger age at the time of surgery $(P=0.007)$ as well age at the time of initial instability $(P=0.03)$ was found to correlate negatively with early recurrence within 2 years of surgery. Among those with recurrent instability, recurrence rate was found to be higher if there had been more than 5 instability episodes preoperatively $(P=0.01)$. Return to the preinjury sport and occupational level was possible in 41 and $78 \%$, respectively.

Conclusion: Failure-free survival rates dropped dramatically over time. Alternative reconstruction techniques should be considered in those aged $\leq 30$ years due to the high recurrence rate.
\end{abstract}

Keywords: Shoulder, Instability, Arthroscopic, Bankart repair, Suture anchors

\footnotetext{
* Correspondence: benpanzram@aol.com

${ }^{\dagger}$ Benjamin Panzram and Yasser Kentar contributed equally to this work.

'Department of Orthopaedic Surgery, Trauma Surgery and Spinal Cord Injury, University of Heidelberg, Heidelberg, Germany

${ }^{2}$ Heidelberg University Hospital, Clinic for Orthopaedics and Trauma Surgery, Schlierbacher Landstraße 200A, 69118 Heidelberg, Germany

Full list of author information is available at the end of the article
}

(c) The Author(s). 2020 Open Access This article is licensed under a Creative Commons Attribution 4.0 International License which permits use, sharing, adaptation, distribution and reproduction in any medium or format, as long as you give appropriate credit to the original author(s) and the source, provide a link to the Creative Commons licence, and indicate if changes were made. The images or other third party material in this article are included in the article's Creative Commons licence, unless indicated otherwise in a credit line to the material. If material is not included in the article's Creative Commons licence and your intended use is not permitted by statutory regulation or exceeds the permitted use, you will need to obtain permission directly from the copyright holder. To view a copy of this licence, visit http://creativecommons.org/licenses/by/4.0/. The Creative Commons Public Domain Dedication waiver (http://creativecommons.org/publicdomain/zero/1.0/) applies to the data made available in this article, unless otherwise stated in a credit line to the data. 


\section{Background}

Various open and arthroscopic techniques have been developed overtime to address the glenohumeral joint instability with the ultimate goal of restoring the shoulder function and lowering the rate of recurrent instability over the long-term. Bankart repair is currently the treatment of choice according to various surveys of surgeons, with $>90 \%$ of surgeons choosing the Bankart procedure as initial repair procedure $[3,4,14]$. A review of the American Board of Orthopaedic Surgery revealed a significant increase in the percentage of arthroscopicallyperformed Bankart repairs was noted, being performed in approximately $88 \%$ of cases between 2006 and 2008, compared to $71 \%$ in the period from 2003 to 2005 [35]. In Germany, more than $90 \%$ use arthroscopic techniques in the first-time dislocation and more than $70 \%$ even in chronic instability, as long as there is not significant bone loss [3]. One of the major advantages of the arthroscopic surgery is the precise identification of the intraarticular pathology with minor soft tissue dissection. In the period between 1995 through 2004, the arthroscopic approach using metallic staples, tacks and transglenoid suturing had twice the risk of postoperative recurrence of instability compared with the open repair [25]. Given the rapid evolution of arthroscopic equipments, techniques, and surgeon's experience, several recent studies showed no superiority of the open technique over the arthroscopic Bankart repair using suture anchors [7, 16, 22, 36].

In respect to recurrent instability after the arthroscopic Bankart repair using suture anchors, the rates have varied widely in the available literature ranging between 3 and 41\% [1, 11, 15, 17, 18, 24, 26, 50, 53]. Several contributors such as the sample size, length of follow up and the definition of postoperative failure might explain this heterogeneity in the aforementioned studies. Several factors including significant bone defects, young age, the number of previous dislocations, time to surgery as well as participation in contact sports could be associated with an increased risk of recurrent instability $[2,8,37,38]$.

The purpose of this study was to report on our experience with arthroscopic Bankart repair using suture anchors and to determine, through a retrospective case series, factors potentially associated with increased postoperative recurrence of instability.

\section{Methods}

\section{Patient selection}

We retrospectively reviewed a consecutive series of patients who underwent primary arthroscopic Bankart repair using suture anchors in the period between January 2004 and December 2014. All patients had a history of a traumatic injury to their shoulder resulting in an anteroinferior shoulder instability confirmed on history, physical examination and magnetic resonance imaging findings. Exclusion criteria were (1) extension of the labrum lesion into the superior labrum (I.e., superior labrum anteriorposterior tear) or posteriorly, (2) atraumatic or multidirectional instability or posterior instability, (3) concomitant rotator cuff tears, (4) arthroscopic stabilization after failed previous repair. A written consent was obtained by all patients who participated in our study.

A total of 100 shoulders fulfilled the study inclusion criteria and were available at the time of the final review.

\section{Operative technique}

Operative technique was carried out in a Beach-chair position using a standard posterior viewing portal in addition to two anterior working portals in the rotator interval, as described in several publications $[23,39,46]$.

After a standardized diagnostic arthroscopy, the Bankart lesion was confirmed and evaluated. Using a Bankart-Chisel, the detached labrum, was mobilized and elevated from the anterior glenoid. An arthroscopic rasp or a shaver was used to create a bleeding bed along the glenoid edge. In all patients, a capsular plication was performed in addition. Using a suture passing instrument, a suture was advanced through the capsulolabral complex to be used as a shuttle suture. Drill holes were created on the glenoid at the 3 and 5:30 o'clock position for the right shoulder and the 6:30 and 9 o'clock for the left shoulder. Additional anchors were placed as necessary. According to the extent of the capsulolabral defect, one to four anchors were used: PushLock ${ }^{\ominus}$ (Arthrex), PANALOK $^{\bullet}$ (DePuy) and Lupine ${ }^{\bullet}$ Loop (DePuy).

\section{Postoperative management}

A sling immobilizer was applied after surgery and worn for 2 weeks. Physical therapy was initiated in the first day after surgery with passive exercises for flexion/abduction/ external rotation $60^{\circ}-60^{\circ}-0^{\circ}$. Active-assisted range of motion was started after 1 week with gradually increase. No heavy lifting and carrying loads over $5 \mathrm{~kg}$ and no contact sports for 12 weeks after operation.

\section{Clinical evaluation and outcome measurement}

We extracted preoperative and intraoperative data retrospectively from medical records. Preoperative assessment included age, age at surgery, age at time of injury, time to surgery (interval between the first instability event and surgery) and number of instability events prior to repair. Participants were divided into 2 groups: Group A with only one episode of subluxation/dislocation and group B with more than one episode. Group B was further subdivided into subgroup B1 with 2-5 episodes and subgroup B2 with more than 5 episodes. Intraoperative findings included type and number of anchors used in the repair. A structured questionnaire was mailed and 
asked to provide type and level of sport activity as well as profession prior to injury. In respect to the type of sport activity prior to injury, participants were grouped in 3 categories: (1) non-contact sports such as tennis, golf, swimming and running, (2) limited-contact sports such as basketball and soccer (3) full-contact sports: such as football, boxing and rugby. According to the level of sport activity, participants were divided intro 3 categories: (1) non-athletes, (2) recreational athletes, and (3) competitive athletes. Type of profession was also classified in 3 groups: group (1) characterizes professions associated with low loads on the shoulder such as office workers, teachers and students, group (2) characterizes professions with moderate loads on the shoulder such as nurses, cooks and gardeners, and group (3) characterizes professions with high loads on the shoulder such as roofers, electrical workers and painters. Postoperative assessment included recurrence of instability where only physician-documented instabilities were considered as a treatment failure. Furthermore, early postoperative recurrence was defined in the current study as those occurring within 2 years of surgery. Clinical outcome and functional activity levels were evaluated using the American Shoulder and Elbow Surgeons Score (ASES), the self-assessment score of shoulder function based on Rowe score [29], and Constant-Murley score. In respect to the strength measurement in the Constant-Murley score, the participants were asked to lift an object with known mass (e.g., water bottle 1 Liter) and hold it for $5 \mathrm{~s}$ in abduction $90^{\circ}$ and slight flexion $20^{\circ}$. One point is given per $0.5 \mathrm{~kg}$. Postoperatively, the level of sport activity as well as the level of occupational performance was measured at six-point licker scale as follows: 1) no change; 2) minimal decrease; 3) slight decrease; 4) moderate decrease; 5) severe decrease; and 6) very severe decrease.

\section{Statistical analysis}

Statistical analysis was performed using SPSS software Version 22 for Windows (SPSS Inc.). Normal distribution of data was tested using the Kolmogorov-Smirnov test before using the Student $t$ test for parametric data or the Mann-Whitney $U$ test for nonparametric data. The chi-square test was used to assess differences between categorical data. In respect to the clinical outcome scores, differences were analyzed by 2 -tailed, paired $\mathrm{t}$ test. The level of significance was set at a $p$ value of $<$ 0.05. Pearson and Spearman correlation tests were used to detect the statistical significance of age/age intervals. The distribution of continuous data such as age, time to surgery and number of anchors used was provided in the form of means, standard deviation, and interquartile range $25-75 \%$. Scores results were given in the form of means and standard deviation. Categorical variables were illustrated by absolute and relative frequencies (count and percentage).

\section{Results}

Base characteristics of the study cohort are presented in (Table 1).

The mean follow-up was 8.3 years (range, 3-14 years). Results of Constant-Murley Score, modified Rowe Score, and American Shoulder and Elbow Surgeons (ASES) Score for both affected/unaffected sides are presented in (Table 2). All scores were postoperative significantly lower than measured values on the unaffected arm. Changes in level of sport activity as well as occupational performance are presented in (Table 3). Overall, $41 \%$ of participants (41 patients) were able to keep the same

Table 1 Baseline characteristics of patients who underwent arthroscopic Bankart repair $(n=100)$

\begin{tabular}{ll}
\hline Variable & Data* \\
\hline Age (years) & $37(29-33)$ \\
Age at surgery (years) & $27.8(19-25)$ \\
Age at first instability event (years) & $23.6(17-29)$ \\
Gender & \\
Male & $76(76 \%)$ \\
Female & $34(24 \%)$ \\
Time to surgery (months) & $51.4(2-57)$ \\
Preoperative instability episodes & \\
Group A: 1 & $33(33 \%)$ \\
Group B: > 1 & $67(67 \%)$ \\
Group B1 [2-5] & $27(40.2 \%)$ \\
Group B2 (> 5) & $40(59.8 \%)$ \\
Dominant side affected & \\
Yes & $57(57 \%)$ \\
No & $43(43 \%)$ \\
No. of suture anchors used & \\
in Bankart repair & $2.5(2-3)$ \\
Preoperative type of sport activity & \\
Non-contact sports & \\
Limited-contact sports & \\
Full-contact sports & $11(11 \%)$ \\
Noonerative level of sport & $20(20 \%)$ \\
Recreational-athletes & $39(69 \%)$ \\
\hline
\end{tabular}

*Values are mean, interquartile range (25-75\%) or $n(\%)$ 
Table 2 Clinical outcomes after arthroscopic Bankart repair $(n=100)$

\begin{tabular}{llll}
\hline Outcome measure & Affected arm $^{* *}$ & Unaffected arm & ${ }^{* * *} P$ value \\
\hline Constant-Murley score & $87 \pm 16$ & $93.4 \pm 8.9$ & 0.000 \\
Modified Rowe score & $91.9 \pm 62.9$ & $95.8 \pm 8.5$ & 0.000 \\
ASES score* & $87.4 \pm 16.3$ & $96.7 \pm 8.2$ & 0.000 \\
\hline
\end{tabular}

*American Shoulder and Elbow Surgeons score, ${ }^{* *}$ Values are mean \pm standard deviation (SD), *** Significance at $P<0.05$

preoperative sport level, whereas $78 \%$ (78 patients) returned to previous occupational level.

Among the 100 shoulders with a follow-up of at least 3 years, postoperative recurrence of instability was reported in $22 \%$ of cases (22 patients). Four participants reported only one episode of postoperative instability; 2 treated conservatively and 2 surgically. On the other hand, 18 participants (18\%) reported two or more instability events; 11 treated conservatively and 7 surgically. The following parameters were found to have a significant negative correlation with postoperative recurrence instability:

\section{Age}

At the time of data analysis, participants who reported recurrence were on average 4 years younger than those who did not $(p=0.11)$. There was a statistically significant negative correlation between younger age at the time of surgery and recurrence rate $(p=0.019$, Pearson correlation coefficient $=0.01$ ). Of the 22 recurrence cases, $86 \%$ of participants were $\leq 30$ years old at the time of surgery ( $p=0.029$, Spearman correlation coefficient $=$ 0.009). On the other hand, age at time of initial instability was not found to be statistically significant in respect to the recurrence rate $(p=0.14$, Pearson correlation coefficient $=0.12$ ). Recurrence rates by age at the time of surgery at 10-year intervals are shown in (Fig. 1).

\section{Number of preoperative instability episodes}

In group $\mathrm{A}$ which includes patients who sustained only one episode of subluxation/dislocation prior surgery, a recurrence rate of $21 \%$ was observed. This was statistically

Table 3 Level of sport and occupational performance decreases after arthroscopic repair

\begin{tabular}{lll}
\hline 6-point Likert scale & Sport performance & Occupational performance \\
\hline Normal & $41(41 \%)$ & $78(78 \%)$ \\
Minimal & $21(21 \%)$ & $11(11 \%)$ \\
Slight & $14(14 \%)$ & $8(8 \%)$ \\
Moderate & $9(9 \%)$ & $1(1 \%)$ \\
Severe & $11(11 \%)$ & $2(2 \%)$ \\
Very severe & $4(4 \%)$ & 0 \\
\hline
\end{tabular}

*Values are $\mathrm{n}(\%)$ not significant ( $p=0.89$ ) compared to group B (22\% recurrence rate) which includes patients with more than one episode. However, a statistically significant difference ( $p=$ 0.003) was found between both subgroups B1, which included those who sustained 2-5 preoperative episodes of instability (3.7\% recurrence rate) and B2, which included those with more than 5 episodes (35\% recurrence rate).

Other factors including gender, time to surgery, dominant side, number of suture anchors used as well as preoperative sport level and occupational shoulder stress were not found to have a significant association with postoperative recurrence of instability. Table 4 summarizes the results observed in both groups.

\section{Recurrence rates of arthroscopic Bankart repair using Kaplan-Meier analysis}

The Kaplan-Meier survival curve for recurrence-free survival is shown in (Fig. 2). The mean estimate for the cumulative proportion of stable shoulders at a mean follow-up of 8 years was 123 months $(\mathrm{SD}=5.6,95 \%$ confidence interval (112-134)). The recurrence-free survival estimates at 1 year, 2 years, 5 years, and 10 years were $91,87,80$, and $70 \%$, respectively.

\section{Early versus late postoperative recurrence}

Twelve patients who developed recurrence within 24 months after surgery were defined as having early recurrence $(54.5 \%)$. In this group, 4 patients suffered a trauma-based postoperative instability: 1 patient experienced following a fall while playing football and 3 patients suffered traumatic recurrence due to physical trauma unrelated to sport. The other 8 recurrence cases occurred during performing tasks of daily activities: 5 while reaching for overhead objects, 2 while sleeping and one by stretching exercises. Seven patients were treated conservatively and 5 operatively.

On the other Hand, 10 patients developed recurrence after 24 months of surgery and were defined as having late recurrence $(55.5 \%)$. Six patients suffered postoperative instability following a non-traumatic event: 4 while reaching for overhead objects and 2 while sleeping. Traumatic events have been reported in the other 4 cases: 1 following a motorcycle collision, 2 after a fall while descending stairs and 1 sustained through skiing. Six patients were treated conservatively and 4 required additional surgery to restore instability.

Both age at the time of surgery as well as age at the time of initial instability showed a significant negative correlation with postoperative recurrence within 2 years. Table 5 summarizes the main differences of patients with early versus late recurrence following Bankart repair for anterior shoulder instability. 


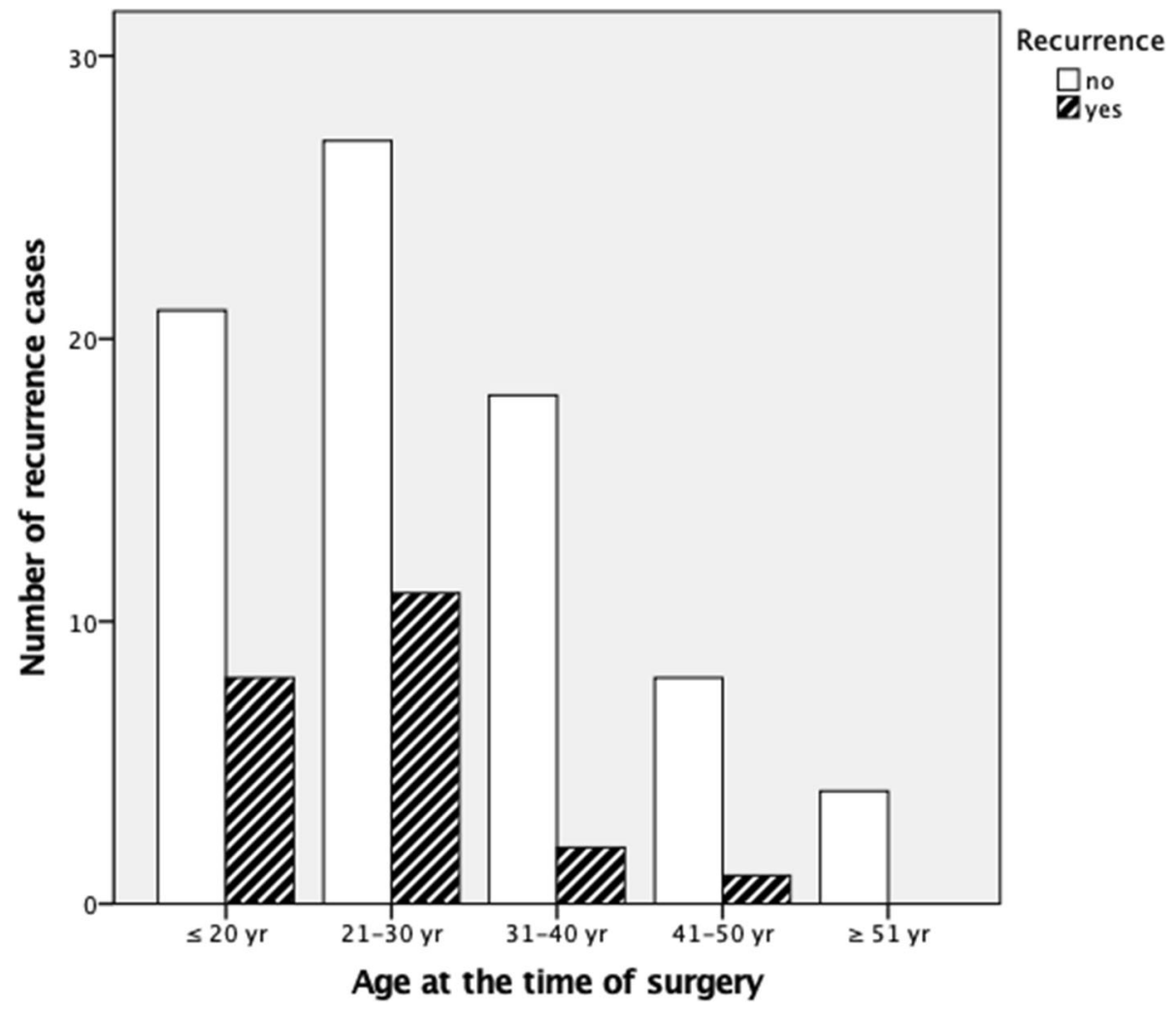

Fig. 1 Recurrence rates by age at the time of surgery at 10-year intervals

\section{Discussion}

The current study included 100 patients who underwent arthroscopic Bankart repair with a mean follow-up of 8.3 years. The postoperative failure rate was $22 \%$. In comparison with the available literature, the findings of the present study appear to be consistent with that of previous studies with long-term follow-up [1, 11, 12, 18]. Castagna et al. reported a recurrence rate at $22.5 \%$ at mean follow-up of 10.9 years [11]. Franceschi et al. reported a recurrence rate at $17 \%$ at mean follow-up of 8 years [18]. Similarly, at minimum follow-up of 13 years, recurrence rate was found to be approximately $18 \%$ [1]. Higher rates of recurrence were reported by Zimmermann at mean follow-up of 6 years (41\%), Van der Linde et al. after a mean follow-up of 9 years $(35 \%)$, and recently by Flinkkila et al. at minimum follow-up of 10 years $(30 \%)[17,50,53]$. The higher recurrence rate in these studies compared to the current investigation could be explained by the fact that the authors defined postoperative failure as any subjective feeling of instability regardless the findings of physical and radiological examinations. They argued that including only patients with physician-documented dislocations/subluxations represents an underestimation of the effect of surgical therapy. Other investigations with smaller sample sizes and/or shorter follow-up periods (24-40 months) reported remarkably lower recurrence rates (range, 3.411\%) $[13,15,21,24,26,32,34]$.

In the current study, recurrence rate appeared to drop significantly with advanced age $(p=0.019)$. This has been supported in several investigations $[27,30,34,38$, 40, 49]. Eighty-six percent of the observed recurrence cases in the current study occurred in patients with the age $\leq 30$ years at the time of surgery $(p=0.029)$. Flinkkila et al. reported in a retrospective study with a minimum of 10 years follow up a remarkably higher recurrence rate in patients younger than 20 years old at the time of surgery ( $54 \%$ vs. $24 \%, p<0.001)$ [17]. This was also supported by Aboalata et al. in a retrospective study with a minimum follow-up of 13 years [1]. The authors divided their patients into 3 categories in respect to the age at surgery; group A included patients younger than 20 years, group B aged 21 to 30 years and group $C$ older than 30 years. The recurrence rate was $39,1,16.1 \%$ and $13,4 \%$, respectively $(p=0.007)$. Considering a cut-off value of 22 years of age, two studies detected a negative correlation concerning age at the time of surgery and recurrence rate $[27,49]$. On the contrary, other studies were not able to establish a significant cut off value [30,34, 51]. It is worth mentioning that other studies showed that age 
Table 4 Associated factors with postoperative recurrence of instability after arthroscopic Bankart repair $(n=100)$

\begin{tabular}{|c|c|c|c|}
\hline \multirow[t]{2}{*}{ Variable } & \multicolumn{2}{|l|}{ Recurrence* $^{*}$} & \multirow[t]{2}{*}{$P$ value ${ }^{* *}$} \\
\hline & Yes $(n=22)$ & No $(n=88)$ & \\
\hline Age (years) & $33.7 \pm 9.3$ & $37.8 \pm 10.6$ & 0.11 \\
\hline Age at surgery (years) & $24 \pm 7.7$ & $28.9 \pm 10.9$ & 0.019 \\
\hline $\begin{array}{l}\text { Age at first instability } \\
\text { event (years) }\end{array}$ & $21.4 \pm 8.5$ & $24.2 \pm 9.9$ & 0.14 \\
\hline \multicolumn{4}{|l|}{ Gender } \\
\hline Male & $17(22.4 \%)$ & $59(77.6 \%)$ & 0.87 \\
\hline Female & $5(20.8 \%)$ & 19 (79.2\%) & \\
\hline $\begin{array}{l}\text { Time to surgery } \\
\text { (months) }\end{array}$ & $31.9 \pm 47.2$ & $56.8 \pm 91.9$ & 0.73 \\
\hline \multicolumn{4}{|l|}{$\begin{array}{l}\text { Preoperative instability } \\
\text { episodes }\end{array}$} \\
\hline Group A: 1 & $7(21.2 \%)$ & $26(78.8 \%)$ & 0.89 \\
\hline Group B: > 1 & 15 (22.4\%) & $52(77.6 \%)$ & \\
\hline Group B1 (2-5) & $1(3.7 \%)$ & $26(96.3 \%)$ & 0.003 \\
\hline Group B2 (> 5) & $14(35 \%)$ & $26(65 \%)$ & \\
\hline Dominant side affected & & & 0.45 \\
\hline Yes & $11(9.3 \%)$ & $46(80.7 \%)$ & \\
\hline No & $11(25.6 \%)$ & $32(74.7 \%)$ & \\
\hline $\begin{array}{l}\text { No. of suture anchors } \\
\text { used in Bankart repair }\end{array}$ & $2.4 \pm 0.6$ & $2.4 \pm 0.6$ & 0.88 \\
\hline Anchor type & & & 0.34 \\
\hline PushLock ${ }^{\circledR}$ & $8(32 \%)$ & 17 (68\%) & \\
\hline PANALOK $^{\oplus}$ & $4(22.2 \%)$ & $14(77.8 \%)$ & \\
\hline LUPINE $^{\oplus}$ & $10(17.5 \%)$ & $47(82.5 \%)$ & \\
\hline $\begin{array}{l}\text { Preoperative type of } \\
\text { sport activity }\end{array}$ & & & 0.45 \\
\hline Non-contact sports & $7(16.3 \%)$ & $36(83.7 \%)$ & \\
\hline Limited-contact sports & $6(24 \%)$ & 19 (76\%) & \\
\hline Full-contact sports & $9(28.1 \%)$ & $23(71.9 \%)$ & \\
\hline $\begin{array}{l}\text { Level of occupational } \\
\text { shoulder stress }\end{array}$ & & & 0.086 \\
\hline Low stress & 19 (27.5\%) & $50(72.5 \%)$ & \\
\hline Moderate stress & 0 & $11(100 \%)$ & \\
\hline High stress & $3(15 \%)$ & 17 (85\%) & \\
\hline
\end{tabular}

at the time of first dislocation (the impact of age at the time of surgery was not taken into consideration) correlated negatively with instability [42-44, 48]. These studies discussed the risk factors for recurrence after anterior shoulder instability in general, not focusing on a specific surgical intervention. This could not be statistically supported in our study, which could be partly referred to the recall bias. Calvo et al. reported in a prospective study of 61 individuals who underwent arthroscopic Bankart repair that age at the time of surgery rather than the age at first dislocation, showed a negative correlation with postoperative failure [9]. Gender seems not to have an impact of postoperative recurrent instability after arthroscopic Bankart repair, which is supported in literature [38]. Furthermore, no association between the recurrence rate and side dominance could be detected, which is also consistent with previous research $[2,17,38,50]$.

Controversial results in respect to the impact of preoperative instability episodes have been presented in the literature. In the study by Imhoff et al., patients with a single preoperative dislocation had a significantly lower rate of postoperative recurrence than patients who had had more than one dislocation prior to arthroscopic repair [27]. A cut-off value of 5 episodes by Habermeyer et al. and less than 4 episodes by Jaeger et al. was reported [20, 28]. In the current investigation, recurrence rates appeared to be similar between those who sustained one episode vs. multiple episodes of instability prior to surgery $(p=0.89)$, which is consistent with several previous investigations $[1,2,11,38,50]$. However, recurrence rates among patients with more than 5 episodes were significantly higher $(p=0.003)$ than those among patients with 2 to 5 episodes.

The results of the current study indicate that the time interval between the first instability event and surgery has no influence on the postoperative recurrence rate $($ Mean $=57.8, p=0.73)$. This is consistent with several previous reports $[1,15,30,51]$. Porcellini et al. found a statistically significant proportional correlation as $68 \%$ of recurrence cases were observed in those who underwent surgery between 6 months and 12 months after initial dislocation in comparison to $32 \%$ in those who underwent surgery within 6 months $(p=0.01)$ [38]. They argued their findings by the capsule elongation and deformation which make the delayed reconstruction much more difficult.

The number of anchors used did not correlate significantly with the recurrence rate in the current study. Boileau et al. and Shibata et al. postulated that four anchors, at a minimum, should be used to secure a better stabilization regardless of the extent of the labral lesion. In both studies, patients who had 3 anchors or less showed significantly higher recurrence rate $[6,47]$. On the contrary, several previous investigations could not show a significant correlation [1, 17, 33].

Return to the preinjury level of sport was possible in $40 \%$ of cases. However, this was not possible in $70 \%$ of patients who participated in full-contact sports. These results are in line with that recent result by Aboalata et al. [1]. Higher rates above $80 \%$ were reported by other authors $[26,32,41]$. No difference in terms of postoperative recurrence rate was observed in this study among the three sport groups (non-contact, limited-contact, and full-contact sports). Several publications reported 


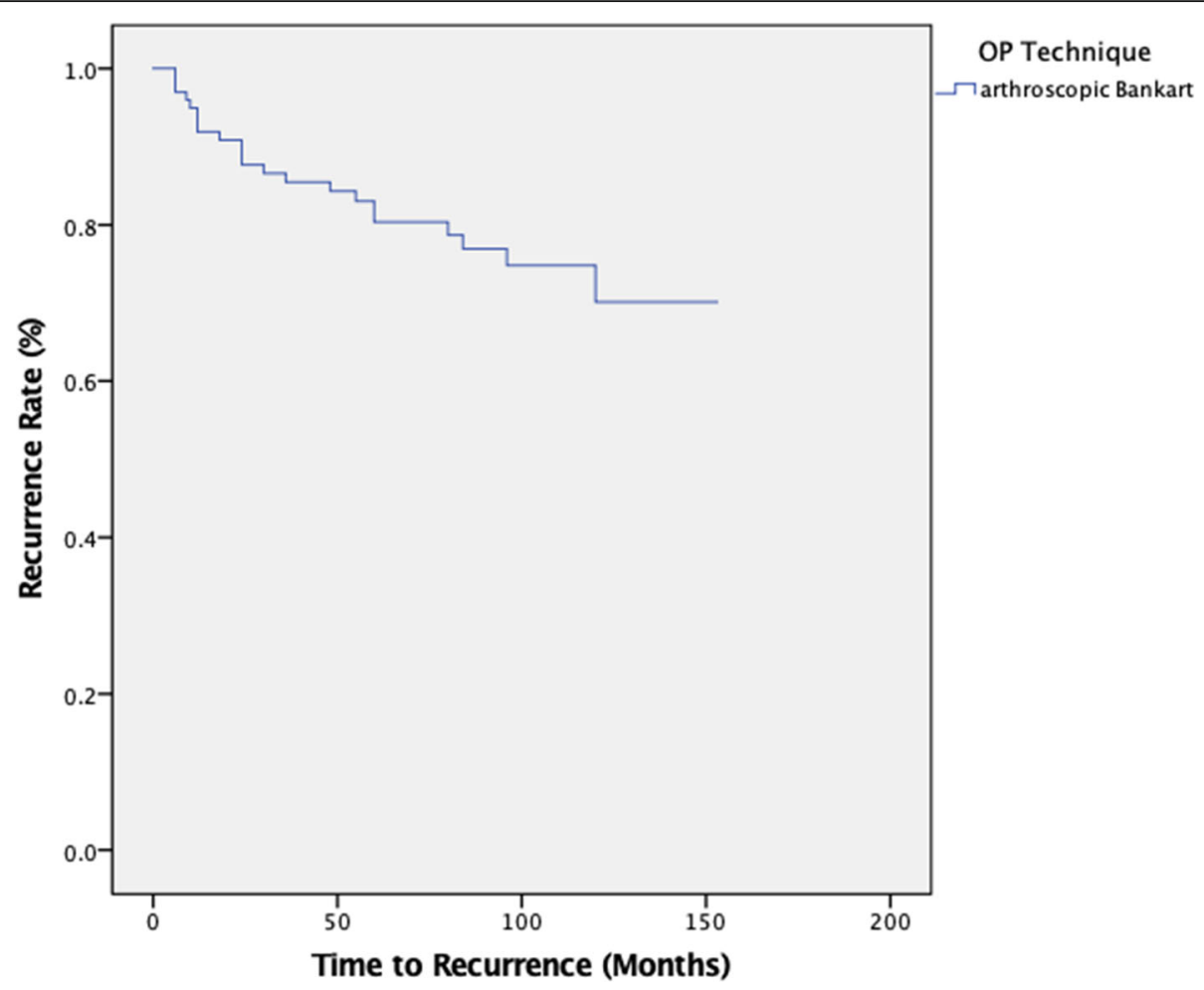

Fig. 2 Recurrence-free survival estimates for arthroscopic Bankart repair

increased risk of recurrence in contact-athletes [11, $52]$, whereas others did not find a significant difference $[10,26]$. Unfortunately, there is a high variability in the classification of sport types that makes the comparison quite difficult. In the current study, approximately $78 \%$ of participants were able to return to the preinjury work level, in comparison to $97 \%$ reported by Franceschi and colleagues [18]. No significant differences of postoperative failure rates among the three work groups were observed.

All postoperative scores showed good (ConstantMurley Score: mean $=87$ and ASES score: mean $=$ 87.4) to excellent (modified Constant score: $m=94.2$ and Rowe score: $m=91.9)$ results, although statistically lower than observed results on the non-affected arm. Similar findings were reported in the literature $[1,19,31,45]$. Franceschi et al. reported a Constant score of 89 and Rowe score of 88 after a mean follow up of 8 years [18]. Excellent Constant, Rowe, and ASES scores (mean $=94,90,92$, respectively) were reported by Aboalata et al. at minimum follow up of 10 years [1].

The current study showed that nearly half of recurrences occurred 2 years after primary surgery. After 2 years, Gerber et al. found that nearly $60 \%$ of recurrence cases $(22 / 36$ of total 271 patients-minimum follow-up 6 years) had not yet occurred [53]. At minimum follow-up of 10 years, Flinkkila et el. reported a similar trend with $50 \%$ of recurrence cases occurring after 2 years after surgery [17]. Likewise, Bessiere et al. and van der Linde et al. have provided further evidence regarding the deterioration of the recurrence rates over time after 6 and 8 years of follow-up, respectively $[5,50]$. In the current investigation, we found that younger age at the time of surgery as well age at the time of initial instability was found to correlate negatively with early recurrence.

The current study has several limitations which can be summarized as follows: (1) The retrospective study design with all of the inherent issues associated with it. (2) No available pre-operative clinical scores for comparison. (3) No available radiographic data and the lack of information regarding the exact range of motion.

\section{Conclusion}

Following the arthroscopic Bankart repair in 100 patients, the Kaplan-Meier failure-free survival estimates were $91 \%$ at 2 years and $70 \%$ at 10 years, which implies a significant drop over time. Failure rate was significantly affected by age at the time of surgery with $86 \%$ of recurrence cases observed in patients aged $\leq 30$ years. This puts the effectiveness of the arthroscopic repair in this age group into question. Nevertheless, younger age at 
Table 5 Characteristics of patients with early versus late recurrence following Bankart repair for traumatic anterior shoulder instability

\begin{tabular}{|c|c|c|c|}
\hline \multirow[t]{2}{*}{ Variable } & \multicolumn{2}{|l|}{ Recurrence* } & \multirow[t]{2}{*}{$P$ value ${ }^{* *}$} \\
\hline & Early $(n=12)$ & Late $(n=10)$ & \\
\hline Age (years) & $29.67 \pm 5.4$ & $40.7 \pm 14.4$ & 0.004 \\
\hline Age at surgery (years) & $21.85 \pm 5.1$ & $31.6 \pm 12.4$ & 0.007 \\
\hline $\begin{array}{l}\text { Age at first instability } \\
\text { event (years) }\end{array}$ & $19.1 \pm 6.2$ & $27.1 \pm 12.6$ & 0.03 \\
\hline \multicolumn{4}{|l|}{ Gender } \\
\hline Male & $9(75 \%)$ & $7(70 \%)$ & 0.79 \\
\hline Female & $3(25 \%)$ & $3(30 \%)$ & \\
\hline \multicolumn{4}{|l|}{ Mechanism of recurrence } \\
\hline Traumatic & $4(33.3 \%)$ & $4(40 \%)$ & 0.74 \\
\hline Non-traumatic & $8(66.7 \%)$ & $6(60 \%)$ & \\
\hline Time to surgery (months) & $27.3 \pm 38.4$ & $55.1 \pm 65.5$ & 0.093 \\
\hline \multicolumn{4}{|l|}{$\begin{array}{l}\text { Preoperative instability } \\
\text { episodes }\end{array}$} \\
\hline Group A: 1 & $2(16.7 \%)$ & $4(40 \%)$ & 0.22 \\
\hline Group B: > 1 & $10(83.3 \%)$ & $6(60 \%)$ & \\
\hline Group B1 [2-5] & $1(10 \%)$ & $2(33.3 \%)$ & 0.24 \\
\hline Group B2 (> 5) & $9(90 \%)$ & $4(66.6 \%)$ & \\
\hline Dominant side affected & & & 0.39 \\
\hline Yes & 7 (58.3\%) & $4(40 \%)$ & \\
\hline No & $5(41.7 \%)$ & $6(60 \%)$ & \\
\hline $\begin{array}{l}\text { No. of suture anchors } \\
\text { used in Bankart repair }\end{array}$ & $2.5 \pm 0.6$ & $2.3 \pm 0.6$ & 0.52 \\
\hline \multicolumn{4}{|l|}{$\begin{array}{l}\text { Preoperative type of } \\
\text { sport activity }\end{array}$} \\
\hline Non-contact sports & $5(41.7 \%)$ & $3(30 \%)$ & \\
\hline Limited-contact sports & $3(25 \%)$ & $3(30 \%)$ & \\
\hline Full-contact sports & $4(33.3 \%)$ & $4(40 \%)$ & 0.85 \\
\hline \multicolumn{4}{|l|}{$\begin{array}{l}\text { Level of occupational } \\
\text { shoulder stress }\end{array}$} \\
\hline Low stress & $11(91.7 \%)$ & $9(90 \%)$ & \\
\hline Moderate stress & 0 & 0 & \\
\hline High stress & $1(8.3 \%)$ & $1(10 \%)$ & 0.089 \\
\hline
\end{tabular}

* Values are mean \pm standard deviation (SD) or $\mathrm{n}(\%)$. ** Significance at $P<0.05$

the time of surgery as well as at the time of initial instability was also associated with early recurrence within 2 years. Among those with recurrent instability, recurrence rate was found to be higher if there had been more than 5 instability episodes preoperatively. Return to the preinjury sport and occupational level was possible in 41 and $78 \%$, respectively. These results have to be interpreted cautiously owing to the limited sample size.

\section{Abbreviations}

ASES: American Shoulder and Elbow Surgeons Score

\section{Acknowledgments}

Not applicable

\section{Authors' contributions}

"B.P contributed to the conception and design of the study, the acquisition of data, interpretation of the results and writing the final manuscript. Y.K contributed to the conception and design of the study, the acquisition of data, interpretation of the results and writing the final manuscript. M.M contributed to the conception and design of the study, provided a critical revision of the manuscript. T.B contributed to the data statistical analysis. P.H contributed to the data extraction from the database. F.Z contributed to the conception and design of the study, provided a critical revision of the manuscript. All authors read and approved the final manuscript".

Funding

The author(s) received no specific funding for this work.

Availability of data and materials

The datasets used and/or analyzed during the current study are available from the corresponding author on reasonable request.

Ethics approval and consent to participate

Heidelberg university institutional review board (Ethics Committee Heidelberg) approved this study. Application number: S-572/2015. A written consent was obtained by all patients who participated in this study.

\section{Consent for publication}

Not applicable

\section{Competing interests}

The authors declare that they have no competing interests.

\section{Author details}

'Department of Orthopaedic Surgery, Trauma Surgery and Spinal Cord Injury, University of Heidelberg, Heidelberg, Germany. ${ }^{2}$ Heidelberg University Hospital, Clinic for Orthopaedics and Trauma Surgery, Schlierbacher Landstraße 200A, 69118 Heidelberg, Germany. Institute of Medical Biometry and Informatics, University of Heidelberg, Heidelberg, Germany. ${ }^{4}$ Ethianum Clinic Heidelberg, Heidelberg, Germany.

Received: 7 February 2019 Accepted: 19 March 2020

Published online: 27 March 2020

\section{References}

1. Aboalata M, Plath JE, Seppel G, Juretzko J, Vogt S, Imhoff AB. Results of arthroscopic Bankart repair for anterior-inferior shoulder instability at 13-year follow-up. Am J Sports Med. 2017;45(4):782-7.

2. Balg F, Boileau P. The instability severity index score. A simple pre-operative score to select patients for arthroscopic or open shoulder stabilisation. J Bone Joint Surg (Br). 2007;89(11):1470-7.

3. Balke M, Shafizadeh S, Bouillon B, Banerjee M. Management of shoulder instability: the current state of treatment among German orthopaedic surgeons. Arch Orthop Trauma Surg. 2016;136(12):1717-21.

4. Berendes TD, Pilot P, Nagels J, Vochteloo AJ, Nelissen RG. Survey on the management of acute first-time anterior shoulder dislocation amongst Dutch public hospitals. Arch Orthop Trauma Surg. 2015;135(4):447-54.

5. Bessiere C, Trojani C, Carles M, Mehta SS, Boileau P. The open latarjet procedure is more reliable in terms of shoulder stability than arthroscopic bankart repair. Clin Orthop Relat Res. 2014;472(8):2345-51.

6. Boileau P, Villalba M, Hery JY, Balg F, Ahrens P, Neyton L. Risk factors for recurrence of shoulder instability after arthroscopic Bankart repair. J Bone Joint Surg Am. 2006;88(8):1755-63.

7. Bottoni CR, Smith EL, Berkowitz MJ, Towle RB, Moore JH. Arthroscopic versus open shoulder stabilization for recurrent anterior instability: a prospective randomized clinical trial. Am J Sports Med. 2006;34(11):1730-7.

8. Burkhart SS, De Beer JF. Traumatic glenohumeral bone defects and their relationship to failure of arthroscopic Bankart repairs: significance of the inverted-pear glenoid and the humeral engaging hill-Sachs lesion. Arthroscopy. 2000;16(7):677-94. 
9. Calvo E, Granizo JJ, Fernandez-Yruegas D. Criteria for arthroscopic treatment of anterior instability of the shoulder: a prospective study. J Bone Joint Surg (Br). 2005;87(5):677-83.

10. Carreira DS, Mazzocca AD, Oryhon J, Brown FM, Hayden JK, Romeo AA. A prospective outcome evaluation of arthroscopic Bankart repairs: minimum 2-year follow-up. Am J Sports Med. 2006;34(5):771-7.

11. Castagna A, Markopoulos N, Conti M, Delle Rose G, Papadakou E, Garofalo R. Arthroscopic bankart suture-anchor repair: radiological and clinical outcome at minimum 10 years of follow-up. Am J Sports Med. 2010;38(10):2012-6.

12. Chalmers PN, Mascarenhas R, Leroux T, Sayegh ET, Verma NN, Cole BJ, et al. Do arthroscopic and open stabilization techniques restore equivalent stability to the shoulder in the setting of anterior glenohumeral instability? A systematic review of overlapping meta-analyses. Arthroscopy. 2015;31(2):355-63.

13. Cho NS, Lubis AM, Ha JH, Rhee YG. Clinical results of arthroscopic bankart repair with knot-tying and knotless suture anchors. Arthroscopy. 2006;22(12): $1276-82$.

14. Chong M, Karataglis D, Learmonth D. Survey of the management of acute traumatic first-time anterior shoulder dislocation among trauma clinicians in the UK. Ann R Coll Surg Engl. 2006;88(5):454-8.

15. Ee GW, Mohamed S, Tan AH. Long term results of arthroscopic Bankart repair for traumatic anterior shoulder instability. J Orthop Surg Res. 2011;6:28.

16. Fabbriciani C, Milano G, Demontis A, Fadda S, Ziranu F, Mulas PD. Arthroscopic versus open treatment of Bankart lesion of the shoulder: a prospective randomized study. Arthroscopy. 2004;20(5):456-62.

17. Flinkkila T, Knape R, Sirnio K, Ohtonen P, Leppilahti J. Long-term results of arthroscopic Bankart repair: minimum 10 years of follow-up. Knee Surg Sports Traumatol Arthrosc. 2017;26(1):94-9.

18. Franceschi F, Papalia R, Del Buono A, Vasta S, Maffulli N, Denaro V. Glenohumeral osteoarthritis after arthroscopic Bankart repair for anterior instability. Am J Sports Med. 2011;39(8):1653-9.

19. Gartsman GM, Roddey TS, Hammerman SM. Arthroscopic treatment of anterior-inferior glenohumeral instability. Two to five-year follow-up. J Bone Joint Surg Am. 2000;82-a(7):991-1003.

20. Habermeyer $P$, Lichtenberg S. Diagnostik und Therapie der vorderen und hinteren Schulterluxation. Chirurg. 2003;74:1178-94. https://doi.org/10.1007/ s00104-003-0771-y

21. Hantes ME, Venouziou Al, Liantsis AK, Dailiana ZH, Malizos KN. Arthroscopic repair for chronic anterior shoulder instability: a comparative study between patients with Bankart lesions and patients with combined Bankart and superior labral anterior posterior lesions. Am J Sports Med. 2009;37(6):1093-8.

22. Harris JD, Gupta AK, Mall NA, Abrams GD, McCormick FM, Cole BJ, et al. Long-term outcomes after Bankart shoulder stabilization. Arthroscopy. 2013; 29(5):920-33.

23. Hendawi T, Milchteim C, Ostrander R. Bankart repair using modern arthroscopic technique. Arthrosc Tech. 2017:6(3):e863-e70.

24. Hoffmann F, Reif G. Arthroscopic shoulder stabilization using Mitek anchors. Knee Surg Sports Traumatol Arthrosc. 1995:3(1):50-4.

25. Hohmann E, Tetsworth K, Glatt V. Open versus arthroscopic surgical treatment for anterior shoulder dislocation: a comparative systematic review and meta-analysis over the past 20 years. J Shoulder Elb Surg. 2017;26(10): 1873-80.

26. Ide J, Maeda S, Takagi K. Arthroscopic Bankart repair using suture anchors in athletes: patient selection and postoperative sports activity. Am J Sports Med. 2004;32(8):1899-905.

27. Imhoff AB, Ansah P, Tischer T, Reiter C, Bartl C, Hench M, et al. Arthroscopic repair of anterior-inferior glenohumeral instability using a portal at the 5:30o'clock position: analysis of the effects of age, fixation method, and concomitant shoulder injury on surgical outcomes. Am J Sports Med. 2010; 38(9):1795-803.

28. Jager A, Kandziora F, Bischof F, Herresthal J. Arthroscopic labral reconstruction for anterior shoulder instability. Failure analysis in 187 patients. Z Orthop Ihre Grenzgeb. 1999;137(1):17-24

29. Jensen KU, Bongaerts G, Schneider S, Bruhn R. Selbsteinschätzungsbogen auf Grundlage des Rowe-Scores von 1982. Obere Extremität. 2009;4(3):178-83.

30. Kandziora F, Jager A, Bischof F, Herresthal J, Starker M, Mittlmeier T. Arthroscopic labrum refixation for post-traumatic anterior shoulder instability: suture anchor versus transglenoid fixation technique. Arthroscopy. 2000;16(4):359-66
31. Kartus J, Ejerhed L, Funck E, Kohler K, Sernert N, Karlsson J. Arthroscopic and open shoulder stabilization using absorbable implants. A clinical and radiographic comparison of two methods. Knee Surg Sports Traumatol Arthrosc. 1998:6(3):181-8.

32. Kim SH, Ha Kl, Kim SH. Bankart repair in traumatic anterior shoulder instability: open versus arthroscopic technique. Arthroscopy. 2002;18(7): 755-63.

33. Mologne TS, Provencher MT, Menzel KA, Vachon TA, Dewing CB. Arthroscopic stabilization in patients with an inverted pear glenoid: results in patients with bone loss of the anterior glenoid. Am J Sports Med. 2007; 35(8):1276-83.

34. Monteiro GC, Ejnisman B, Andreoli CV, de Castro PA, Cohen M. Absorbable versus nonabsorbable sutures for the arthroscopic treatment of anterior shoulder instability in athletes: a prospective randomized study. Arthroscopy. 2008:24(6):697-703.

35. Owens BD, Harrast JJ, Hurwitz SR, Thompson TL, Wolf JM. Surgical trends in Bankart repair: an analysis of data from the American Board of Orthopaedic Surgery certification examination. Am J Sports Med. 2011:39(9):1865-9.

36. Owens BD, Cameron KL, Peck KY, DeBerardino TM, Nelson BJ, Taylor DC, et al. Arthroscopic versus open stabilization for anterior shoulder subluxations. Orthop J Sports Med. 2015;3(1):2325967115571084.

37. Ozbaydar M, Elhassan B, Diller D, Massimini D, Higgins LD, Warner JJ. Results of arthroscopic capsulolabral repair: Bankart lesion versus anterior labroligamentous periosteal sleeve avulsion lesion. Arthroscopy. 2008;24(11): 1277-83.

38. Porcellini G, Campi F, Pegreffi F, Castagna A, Paladini P. Predisposing factors for recurrent shoulder dislocation after arthroscopic treatment. J Bone Joint Surg Am. 2009;91(11):2537-42.

39. Raiss P, Zeifang F. Vordere Instabilität - arthroskopische Technik. In: Lehmann L-J, Loew M, editors. Schulter. Berlin: Springer Berlin Heidelberg; 2018. p. 73-82.

40. Randelli P, Ragone V, Carminati S, Cabitza P. Risk factors for recurrence after Bankart repair a systematic review. Knee Surg Sports Traumatol Arthrosc. 2012;20(11):2129-38

41. Rhee $Y G, H a J H$, Cho NS. Anterior shoulder stabilization in collision athletes: arthroscopic versus open Bankart repair. Am J Sports Med. 2006;34(6):979-85.

42. Robinson CM, Howes J, Murdoch H, Will E, Graham C. Functional outcome and risk of recurrent instability after primary traumatic anterior shoulder dislocation in young patients. J Bone Joint Surg Am. 2006; 88(11):2326-36

43. Sachs RA, Lin D, Stone ML, Paxton E, Kuney M. Can the need for future surgery for acute traumatic anterior shoulder dislocation be predicted? Bone Joint Surg Am. 2007:89(8):1665-74.

44. Safran O, Milgrom C, Radeva-Petrova DR, Jaber S, Finestone A. Accuracy of the anterior apprehension test as a predictor of risk for redislocation after a first traumatic shoulder dislocation. Am J Sports Med. 2010:38(5):972-5.

45. Segmüller HE, Hayes MG, Saies AD. Arthroscopic repair of glenolabral injuries with an absorbable fixation device. J Shoulder Elb Surg. 1997;6(4): 383-92.

46. Seo J-B, Heo K, Yang J-H, Yoo J-S. Two portal technique with antegrade suture passer and knotless anchors for arthroscopic Bankart repair: a technical note. J Arthrosc Joint Surg. 2019:6:31-4.

47. Shibata H, Gotoh M, Mitsui Y, Kai Y, Nakamura H, Kanazawa T, et al. Risk factors for shoulder re-dislocation after arthroscopic Bankart repair. J Orthop Surg Res. 2014;9:53.

48. te Slaa RL, Brand R, Marti RK. A prospective arthroscopic study of acute firsttime anterior shoulder dislocation in the young: a five-year follow-up study. J Shoulder Elb Surg. 2003;12(6):529-34.

49. Thal R, Nofziger M, Bridges M, Kim JJ. Arthroscopic Bankart repair using knotless or BioKnotless suture anchors: 2- to 7-year results. Arthroscopy. 2007:23(4):367-75

50. van der Linde JA, van Kampen DA, Terwee CB, Dijksman LM, Kleinjan G, Willems WJ. Long-term results after arthroscopic shoulder stabilization using suture anchors: an 8- to 10-year follow-up. Am J Sports Med. 2011;39(11): 2396-403.

51. Voos JE, Livermore RW, Feeley BT, Altchek DW, Williams RJ, Warren RF, et al. Prospective evaluation of arthroscopic bankart repairs for anterior instability. Am J Sports Med. 2010;38(2):302-7. 
52. Yamamoto N, Kijima H, Nagamoto H, Kurokawa D, Takahashi H, Sano H, et al. Outcome of Bankart repair in contact versus non-contact athletes. Orthop Traumatol Surg Res. 2015;101(4):415-9.

53. Zimmermann SM, Scheyerer MJ, Farshad M, Catanzaro S, Rahm S, Gerber C. Long-term restoration of anterior shoulder stability: a retrospective analysis of arthroscopic Bankart repair versus open Latarjet procedure. J Bone Joint Surg Am. 2016;98(23):1954-61.

\section{Publisher's Note}

Springer Nature remains neutral with regard to jurisdictional claims in published maps and institutional affiliations.

Ready to submit your research? Choose BMC and benefit from:

- fast, convenient online submission

- thorough peer review by experienced researchers in your field

- rapid publication on acceptance

- support for research data, including large and complex data types

- gold Open Access which fosters wider collaboration and increased citations

- maximum visibility for your research: over $100 \mathrm{M}$ website views per year

At $\mathrm{BMC}$, research is always in progress.

Learn more biomedcentral.com/submissions 